\title{
O problema do pensamento outro em Alexandre Koyré e Lucien Febvre*
}

\author{
The problem of forms of thinking "other" than ours in Alexandre Koyré \\ and Lucien Febvre
}

\author{
Marlon Salomon \\ marlonsalomon@gmail.com \\ Professor associado \\ Universidade Federal de Goiás \\ Campus Samambaia - Cx. Postal 131 \\ 74001-970 - Goiânia - GO \\ Brasil
}

\begin{abstract}
Resumo
O objetivo deste artigo é reconstituir os termos de uma breve controvérsia ocorrida no final da década de 1940 entre Alexandre Koyré e Lucien Febvre em torno da interpretação da formação da ciência moderna e do nascimento da tecnologia na Europa do século XVII. Por meio da análise dessa controvérsia, podemos não apenas compreender o modo como se constituíram na França duas maneiras singulares de conceber a história das ciências, mas também e, sobretudo, mostrar como elas eram mobilizadas por um problema comum. Desde o início do século XX, as formas de pensamento que não eram as "nossas" não podiam mais ser compreendidas a partir de uma concepção evolucionista da razão. Era preciso, doravante, fundar essa compreensão em outra perspectiva. Não se podia mais tomar as formas do pensamento outro como 124 formas proscritas, degredadas ou inatuais do pensamento. A história das mentalidades e a história do pensamento científico, por vias distintas, buscaram responder a esse problema.
\end{abstract}

\section{Palavras-chave}

Historiografia francesa; História da ciência; História das mentalidades.

\begin{abstract}
The aim of this paper is to reconstitute the terms of a short controversy that took place in the late 1940 s between Alexandre Koyré and Lucien Febvre regarding the constitution of modern science and the birth of technology in seventeenth-century Europe. By analyzing this controversy, it is possible not only to recognize how two singular ways of understanding the history of science have emerged in France, but also, and above all, to show how they were mobilized by a common issue. Since the early twentieth century, ways of thinking that are different from "our own" could no longer be understood based on an evolutionary conception of reason. It became henceforth clear that ways of thinking "other" than ours could no longer be regarded as proscribed, banished or outdated forms of thought. By different routes, Febvre's history of mentalities and Koyré's history of scientific thought sought to solve this very same problem.
\end{abstract}

\section{Keywords}

French historiography; History of science; History of mentalities.

Recebido em: 22/11/2013

Aprovado em: 1/5/2014

\footnotetext{
* Os resultados deste artigo fazem parte de uma pesquisa de pós-doutoramento realizada na École de Hautes Études en Sciences Sociales (EHESS), em Paris, que contou com apoio da Coordenação de Aperfeiçoamento de Pessoal de Nível Superior (CAPES), por meio de uma bolsa de Estágio Sênior. Este trabalho faz parte de um estudo mais amplo sobre a concepção de história de Alexandre Koyré, que conta com apoio do Conselho Nacional de Desenvolvimento Científico e Tecnológico (CNPq), por meio de uma bolsa de produtividade.
} 
Em 1951, diante da Assembleia de Professores do Collège de France, Lucien Febvre intervinha a favor da criação de uma cátedra de "História do Pensamento Científico", para a qual propunha a nomeação de Alexandre Koyré. Não se tratava de um ensino puramente técnico da ciência, pois, no estudo da obra de grandes espíritos, tais como Copérnico, Kepler, Galileu e Newton, encontrava-se inscrita a própria possibilidade de compreensão do que a "civilização moderna do Ocidente" subentendia como o que a caracterizava e distinguia, desde o século XVI, de outras civilizações. Apenas alguns meses antes, Febvre se referia ao historiador e filósofo francês de origem russa como aquele "que melhor conhecia, então, na França, a história comparada da Ciência e da Técnica no tempo de Galileu e de seus sucessores" (FEBVRE 1950, p. 25). Mas não era apenas em razão de suas "ideias novas, vigorosas, originais e vivificantes", das quais a história das civilizações era devedora, que Febvre reclamava os votos de seus colegas. Era preciso preencher uma verdadeira lacuna institucional então existente na França, abrir o Collège de France ao ensino de pesquisas que não se praticavam alhures e impedir que se perdesse a ocasião de recrutar, em uma época em que eles se faziam raros, um "espírito original" (FEBVRE 1986, p. 134).

Graças aos documentos que Pietro Redondi fez publicar, conhecemos o fim dessa história e o malogro desse esforço que reuniu em torno de um projeto comum, naquele momento, Febvre e Koyré. Alguns anos mais tarde, esse projeto seria institucionalizado na VIa Seção da École Pratique de Hautes Études (EPHE), então presidida por outro eminente historiador, Fernand Braudel. De sua parte, Koyré sempre insistiu em apresentar Febvre, sobretudo nos Estados Unidos, como "o grande historiador [...] que tanto fez pela renovação dos estudos históricos na França" (KOYRÉ 1982b, p. 97).

No entanto, malgrado esse projeto comum e esse mútuo reconhecimento da importância de ambos os trabalhos, é interessante reconhecer uma breve controvérsia entre Febvre e Koyré, na segunda metade da década de 1940, a propósito da interpretação da formação da ciência moderna e do nascimento da tecnologia no mundo ocidental. Se, por meio da reconstituição dessa controvérsia, podemos dar relevo a duas concepções de história das ciências, a modos distintos de pensar a relação entre ciência e realidade, a maneiras diferentes de compreender o tempo histórico e a distinção entre os conceitos de mentalidade e pensamento, acreditamos que nela subjaz um problema que marcou um conjunto importante e diversificado de esforços, na primeira metade do século $X X$, aquele sobre como tratar, de um ponto de vista histórico e filosófico, as formas de pensamento que não são as "nossas", o problema do pensamento outro. Eis o que gostaríamos de analisar neste artigo.

\section{Um programa}

Lucien Febvre dedicou um capítulo importante de seu $O$ problema da descrença no século XVI. A religião de Rabelais à história das técnicas e das ciências. Seu objetivo ali era tratar da possibilidade da constituição da ciência no século XVI. Seu interesse pela história das ciências e das técnicas não era, contudo, novo no início dos anos 40. Desde ao menos 1924, Febvre se dedicava 
a escrever resenhas e críticas de livros publicados sobre esses domínios. Não se trata aqui de inventariar esse arquivo de textos, mas apenas de apontar o interesse dos Annales pela instituição de uma história das ciências e das técnicas. Paralelamente a um esforço de renovação metodológica, a um trabalho de ampliação dos domínios de investigação, tratava-se de exortar a instituição de uma nova disciplina e de definir-lhe um programa mínimo. A arquivologia desses textos certamente permitiria descrever a formação desse programa.

Se, para Febvre, não havia então uma história das ciências era porque, basicamente, aqueles que se dedicavam ao estudo da ciência no passado filósofos e cientistas -, analisavam-na em um espaço ideal e sem relação com a época de sua produção e formação. Era preciso situá-la "em seu tempo". Era preciso escrever uma "história histórica" das ciências e das técnicas - Febvre estendia essa mesma crítica ao modo como os filósofos tratavam os textos antigos da história da filosofia - situando-as em seu tempo, quer dizer, em relação a outros domínios do conhecimento, em relação a outras esferas de valor de uma época. A atividade técnica, ele escrevia em 1935,

não poderia ser isolada das outras atividades humanas. Fortemente enquadrada por todas elas, ela é comandada por suas ações, individual e coletiva. Quer se trate da religião, da arte ou da política - necessidades militares ou sociais dos grupos humanos constituídos [...]. Cada época tem sua técnica e esta técnica tem o estilo da época. Um estilo que mostra a que ponto tudo se encadeia e se interfere nos fatos humanos: como, se assim se preferir, a técnica sofre a influência do que se pode nomear a história geral - e, ao mesmo tempo, age sobre esta história (FEBVRE 1935, p. 532-533).

Eis, então, um argumento programático: é preciso situar a técnica e a ciência em sua época num quadro de relações que as articule com todas as outras atividades humanas de um período. Eis, então, o programa de uma história totalizante.

É exatamente esse programa que encontramos desenvolvido no capítulo III do Livro II de Rabelais intitulado "Os apoios da irreligião: as ciências?". A tese por ele sustentada, ao longo do livro, é a de que Rabelais não poderia ser um descrente no século XVI. Essa era a tese de Abel Lefranc, apresentada na introdução de Pantagruel, publicada na edição crítica das Obras, de 1922. Segundo Lefranc, desde o início de sua carreira literária, Rabelais aderira ao racionalismo. Era, portanto, um "ateu militante", um "crente da incredulidade"; um homem que, em pleno século XVI, dissimulava em sua literatura a defesa da emancipação religiosa. Portanto, um homem à frente de seu tempo, "um precursor dos ateus e dos libertinos do século XVIII" (FEBVRE 1970, p. 26-27). O problema de Febvre, apresentado em sua "Nota Liminar", não será o de saber se Rabelais era ou não um descrente, mas se era ou não possível sê-lo nessa época (FEBVRE 1970, p. 29).

Para Febvre, a tese de Lefranc incorria no imperdoável pecado do anacronismo ao atribuir um fenômeno a um tempo que não preenchia as condições que tornariam possível a possibilidade de sua constituição. No século 
XVI, a existência, em todas as suas dimensões (pessoal, coletiva, íntima, pública, privada, intelectual etc.), era ritmada pelo cristianismo. Não era possível, assim, nesse tempo, não ser crente. Um racionalista apenas poderia aí aparecer se se apoiasse em outras bases. Era preciso, assim, contar com sólidos apoios que permitissem a alguém sobre-erguer a cabeça a essa atmosfera e fundar em sólidas e válidas razões o livre pensamento. É justamente então que ele introduz o problema da ciência no século XVI.

\section{Um quadro das condições de pensamento}

A invenção da imprensa permitiu reunir e dispor facilmente de textos e manuscritos que se encontravam dispersos e fragmentados. Produziu uma nova base material para o estudo a partir da qual era possível construir sistemas, teorias ou, ao menos, interpretar e comentar o saber antigo. Essa nova base material explica, parcialmente, a modalidade de conhecimento sobre a natureza no século XVI: não se tratava de interpretar o saber antigo, mas de retocá-lo, complementá-lo. Eis o trabalho sobre as plantas, de Otto Brunfels, sobre os animais, de Gessner, sobre os minerais, de Pierre Belon; recenseamentos de toda "natureza viva"; organizações de inventários; catálogos que ganharam o mundo através da imprensa. Por outro lado, o que explica a própria forma infinita do inventário que então se impôs e que um Gessner arrolasse em sua compilação, lado a lado, seres reais e imaginários é que se tratava de um conhecimento "por ouvir dizer". Para que esse limiar fosse vencido, era preciso que houvesse controle empírico e verificação dos fatos. É o que explica certa ingenuidade desses inventários que registravam tudo: não se criticava ou se verificava o que se compilava. Para que houvesse verificação, era preciso dispor de ferramentas e instrumentos científicos. Mas, mesmo que houvesse instrumentos científicos, não havia linguagem que tornasse possível medir o que se observasse ou verificasse. Os métodos de cálculo não estavam unificados, e a notação matemática variava de um lugar para outro. Os símbolos não eram suficientes. Havia resistência ao cômodo emprego dos algarismos árabes. Desconhecia-se nossa aritmética regular e moderna. A álgebra era desconhecida. Não havia, portanto, linguagem matemática que pudesse traduzir, expressar ou mesmo tornar possível o emprego de instrumentos científicos caso eles existissem. Ora, a ciência não poderia progredir sem uma língua que ela pressupõe. Havia, assim, uma carência de ordem liguageira e simbólica que bloqueava a formação da ciência.

Esses limites desenham, mesmo que parcialmente, o que Febvre denomina "quadro das condições de pensamento de um século" (FEBVRE 1970, p. 443). O que o quadro dessas condições - não do que se pensou, mas do que era possível ser pensado - aponta é que "nem o pensamento dos homens desse tempo podia ter força convincente - nem sua ciência força subjacente" (FEBVRE 1970, p. 444). Quer dizer, não apenas não poderia haver ruptura com a credulidade como Rabelais não poderia ser um proselitista precursor dos ateus do século das Luzes. A tese de Febvre destrona, desse modo, não apenas a concepção heroica e burckhardtiana de Renascimento e seus ídolos, mas os argumentos tradicionais sobre a existência de homens à frente de seu tempo. De toda 
forma, não nos interessa aqui circunscrever sua análise à tese geral do livro sobre a impossibilidade da descrença no século XVI, mas sim considerar sua concepção de história das ciências. Duas questões parecem ser interessantes a esse respeito.

\section{Nicolau Copérnico e a astronomia no século XVI}

A primeira delas diz respeito ao estatuto que Febvre atribui à astronomia no século XVI. Evidentemente, ele não poderia deixar de considerar em sua análise as teorias astronômicas, particularmente, a teoria heliocêntrica. Em 1543, Nicolau Copérnico estabeleceu um novo sistema astronômico no qual afirmava a hipótese de uma Terra móvel girando em torno de um Sol estacionado no centro do cosmos. A interpretação da teoria heliocêntrica coloca o problema do valor das hipóteses em ciência e, principalmente, da relação das hipóteses científicas com a realidade que elas afirmam.

Essa é uma questão epistemológica fundamental no início do século XX - e que assumirá contornos distintos em diferentes contextos historiográficos. Os textos reunidos em Combates pela história (1995) mostram como, de um ponto de vista metodológico, afirmando a natureza teórica do conhecimento científico, e de um ponto de vista filosófico, pensando a ciência histórica em relação a essa nova compreensão de ciência, Febvre é bastante consciente das profundas transformações que marcam os diferentes domínios científicos naquele período (REDONDI 1983; GATTINARA 1998). Em 1941, ele escreve, por exemplo, que

128 duas operações se encontram "na base de todo trabalho científico moderno [de sua época]: colocar problemas e formular hipóteses" (FEBVRE 1995, p. 22). A ciência - Febvre não está tratando apenas da história, mas, antes, relacionando-a com o que se passa em outros domínios -, a ciência não observa e registra, ela interpreta. Estamos distantes de uma concepção positivista, empirista e determinista de ciência. ${ }^{1}$

Em 1908, Pierre Duhem definia o valor da noção de teoria em ciência. A astronomia, primeira teoria física matemática, nasce pela divisa "salvar as aparências". Foi Platão quem estabeleceu o problema pela questão formulada aos matemáticos: "quais são os movimentos circulares, uniformes e perfeitamente regulares que convêm tomar por hipóteses, a fim de que se possa 'salvar as aparências' apresentadas pelos planetas?" (DUHEM 2003, p. 13). Mas Pierre Duhem também apresentava uma interpretação fenomenista da máxima platônica. Para ele, não se tratava de um esforço de pensamento que buscava produzir uma representação verdadeira dos movimentos dos corpos celestes. "As hipóteses dos astrônomos não sendo absolutamente realidades, mas somente ficções cujo objetivo é salvar as aparências, não seria surpresa o fato de que diferentes astrônomos tentem atingir este objetivo usando hipóteses diferentes" (DUHEM 2003, p. 35-36). "Somente ficções", diz Duhem:

\footnotetext{
${ }^{1}$ Essa compreensão da natureza teórica do conhecimento científico sugere uma forte proximidade com a perspectiva de Alexandre Koyré, para quem a ciência é fundamentalmente elaboração teórica sistemática. Daí o interesse em acompanhar a interpretação febvriana sobre a ciência no século XVI, já que seus pronunciamentos teóricos sobre ela sugerem uma posição comum com seu contemporâneo.
} 
as hipóteses são apenas expedientes, "artifícios matemáticos" (DUHEM 2003, p. 152) sem relação com a verdade e com o mundo; importa que elas salvem as aparências, isto é, que permitam, por meio de cálculos, prever a posição futura dos planetas. Dessa forma, Duhem interpretava o nascimento da ciência e, ao mesmo tempo, rejeitava uma noção de conhecimento totalmente fundada na experiência, conforme ao positivismo tradicional. Mas não era apenas isso, pois ele renovava uma concepção positivista de ciência assimilando-a a uma interpretação convencionalista e irrealista do conhecimento científico.

A interpretação de Febvre retoma a leitura de Duhem sobre a situação da astronomia no século XVI - a oposição entre "filósofos" e "matemáticos" etc. - e, ao mesmo tempo, permite inferir que o Nicolau Copérnico de Febvre é de segunda mão. ${ }^{2}$ Contudo, se é um Copérnico de segunda mão que encontramos em sua pena, é original a explicação que Febvre fornece para o estado em que então se encontravam as teorias astronômicas. O que tinha feito Copérnico diante da oposição entre averroistas e discípulos de Ptolomeu?

Escolheu afastar uns e outros, e formular uma nova hipótese. "Impossível" talvez ao olhar do físico; mas não há hipótese impossível para o geômetra, desde que formulando-a, e apoiando-se nela, consegue guardar as aparências celestes e efetuar cálculos rigorosos [...] Com efeito, a hipótese parece confirmar todas as aparências, "salva todos fenômenos". Processo julgado: pode ser adotada (FEBVRE 1970, p. 447).

Para Febvre, embora Copérnico se alinhasse ao lado dos realistas, ele falava como "astrônomo-geômetra". E aqui tocamos no segundo ponto que gostaríamos de sublinhar de sua concepção de história das ciências. O próprio Duhem alinhava Copérnico ao lado dos realistas. Mas a despeito de Copérnico - e de Galileu e Kepler -, Duhem afirmava o caráter puramente convencional das hipóteses matemáticas e teorias físicas. Febvre, no entanto, ao situar o heliocentrismo entre outras hipóteses astronômicas, não partilha do convencionalismo duhemiano. Ele o inscreve no mesmo tipo de limites em que situava os inventários da natureza do século XVI.

Referindo-nos ao heliocentrismo ou à mobilidade da Terra, poderíamos falar da produção de uma nova verdade? Para Febvre, apenas se houvesse critérios que o permitissem. O que afirmava Copérnico não era nada mais do que um "ato de fé". Faltava a demonstração de sua hipótese. Isso se explica pelos "tempos": a carência material e instrumental era um limite instransponível. Febvre aplica a Copérnico e à astronomia do século XVI o argumento sobre a carência material que então limitava a formação da ciência. O tempo de Copérnico e de seus raciocínios não dispunha de materiais que tornassem possível a demonstração de suas hipóteses. Daí que salvar as aparências, i.e., formular uma hipótese geométrica sobre os movimentos dos planetas fosse possível, mas não demonstrá-la ou, como ele escreve, "agarrar-se à

${ }^{2}$ Pois, embora elelisteo DeRevolutionibusnabibliografia final dolivro, elenãoocita diretamenteemmomentoalgum. Damesmaforma, éinteressanteobservarqueFebvreretomaDuhem (enãootextodeKoyré[1934] sobreCopérnico): com o autor de Salvar as aparências, ele partilha uma interpretação antirrevolucionária da história das ciências. 
realidade" (FEBVRE 1970, p. 444). O heliocentrismo não poderia ser, assim, um acontecimento. "Eram precisas provas experimentais e decisivas. Era preciso que a observação estabelecesse, claramente, indiscutivelmente, a analogia da constituição dos planetas e da Terra; ora o telescópio ainda não nascera". E sem ele, Galileu não descobriria as manchas do Sol e não poderia, portanto, refutar o dogma da incorruptibilidade dos céus. A tese de Lucien Febvre é bastante clara: a existência, no século XVI, de diferentes sistemas do mundo, todos prováveis por inúmeros motivos, justifica-se por "razões de observação e de experiência". Isso explica por que, a partir de Galileu, a partir do momento em que é possível submeter essas diferentes hipóteses à verificação, encerra-se com esses diferentes sistemas e a teoria copernicana se impõe. Percebe-se que, para contornar o argumento convencionalista de Duhem, Febvre se funda em uma concepção bastante tradicional de verdade.

Daí o estatuto que Febvre atribui à ciência de então: "opiniões" (FEBVRE 1970, p. 444). Daí o problema do estatuto da verdade: "haverá verdade no domínio das ciências no dia em que, de duas opiniões que não são senão opiniões, se puder controlar que uma é verificada pelos fatos, a outra desmentida ou não confirmada por eles. Esse dia ainda não chegara no século XVI" (FEBVRE 1970, p. 463). Era preciso esperar pela ciência experimental. Somente uma hipótese "verificada pelos fatos traduz-se, finalmente, por verdadeira" (FEBVRE 1970, p. 463). É preciso, portanto, cautela ao se falar de ciência ou projetar nossa "concepção moderna de ciência sobre o saber dos Antigos". Ou melhor, é

130 preciso evitar seu emprego: "A ciência: esse singular vem-nos aos lábios, sem esforço, em 1941. Ou ainda, se nos for preciso fazer esforço, é para nos impedir de o empregar, falando do tempo de Rabelais - porque é um anacronismo" (FEBVRE 1970, p. 464). Vemos como ele situa a teoria heliocêntrica no tempo da credulidade: ela se funda em crenças e em opiniões.

\section{Evolução da lógica e o conceito de mentalidade}

Há uma série de questões que poderíamos destacar sobre o modo como Febvre interpreta a astronomia no século XVI. Para o que nos interessa neste momento, seria interessante sublinhar a crítica à concepção positivista implícita em sua interpretação a partir do conceito de mentalidade. Trata-se de uma crítica à ideia de um aperfeiçoamento contínuo e progressivo do espírito humano por meio do qual as concepções mágicas e religiosas da natureza teriam sido substituídas por concepções baseadas na formulação de leis e fundadas na observação dos fenômenos (COMTE 1983, p. 3). Essa concepção positivista implicava a afirmação da impossibilidade de coexistência de racionalismo e credulidade, ou da "incompatibilidade" entre teologia e física. É nessa concepção que se apoiava a ideia de uma história das ciências como história da evolução da lógica. O que é importante: as formas do pensamento outro eram inscritas em uma grade evolutiva e linear de compreensão da razão, tomadas como etapas vencidas ou ultrapassadas de um progresso necessário.

É aí que a noção de mentalidade e seu emprego devem ser aqui considerados. É consabido que a noção de mentalidade é devida a Lucien 
Lévy-Bruhl. Situando-se em um problema aberto por Comte, mas partindo do conceito durkeimiano de "representações sociais", o autor de Funções mentais nas sociedades inferiores esforçava-se por caracterizar, a partir de 1910, a singularidade da "mentalidade primitiva" (LÉVY-BRUHL 1928). Tratava-se de mostrar que o caráter essencialmente místico (no sentido de crença na existência de forças invisíveis, influências e ações imperceptíveis) era o traço que melhor a caracterizava. E, mais, que as representações coletivas e a forma como elas se ligavam entre si eram absolutamente distintas nos primitivos ou nas "sociedades inferiores". Lévy-Bruhl demarcava uma diferença não de grau, mas de natureza, uma variação entre o "nosso" pensamento e a mentalidade primitiva. Assim, do ponto de vista de sua orientação ou dos conteúdos de suas representações, a mentalidade primitiva era mística. Do ponto de vista do modo como essas representações se ligavam entre si, era prélógica. O prefixo "pré" aí não se refere à cronologia, a um estado historicamente datável e anterior ao aparecimento da lógica (GOLDMAN 1994). E o radical "lógica", no sentido peripatético, refere-se ao fato de que a mentalidade primitiva não se sujeita ao princípio de contradição: os Bororos afirmam, ao mesmo tempo, serem araras e homens. Assim, Lévy-Bruhl opunha uma mentalidade prélógica a um pensamento lógico e afirmava que a mentalidade primitiva obedecia a leis absolutamente distintas da nossa lógica. Ao mesmo tempo, ele colocava em questão a compreensão evolucionista, irreversível e ternária comtiana, segundo a qual o estado científico ou positivo, inaugurado no século XVII por Bacon, substituiria o estado metafísico, teológico ou religioso. Isso marca uma ruptura filosófica importante, pois implica considerar o pensamento que não é o "nosso" como alteridade independente de uma escala evolutiva.

Para Pietro Redondi, é essa oposição, retrabalhada por Charles Blondel no final dos anos 1920, que torna possível, na França da década de 1930, a história das mentalidades entendida como pesquisas "de psicologia histórica consagradas ao estudo da recorrência de mentalidades prélógicas mesmo em fases da civilização" (REDONDI 1983, p. 312-313). Podia-se supor, a partir de então, a existência de quadros de relações (entre representações coletivas e os meios de sua ligação) autônomos em um determinado período no interior de uma mesma cultura - sem precisar recorrer ao estudo de outras culturas. É o que explica, ao mesmo tempo, o interesse, então, pelo Renascimento. O hermetismo, a magia e o misticismo do século XVI transformavam o Renascimento naquilo que o historiador italiano define como "um laboratório privilegiado para a aplicação histórica da noção de mentalidade" (REDONDI 1983, p. 313). As práticas mágicas e a compreensão de natureza constituída pela ação de forças invisíveis poderiam ser pensadas a partir de outra lógica. Na ausência de utensilagem mental, de aparelhagem material e linguageira, a incredulidade tornava-se uma impossibilidade no século XVI, e a sua mentalidade permanecia, de resto, primitiva. No último capítulo de seu Rabelais, Febvre se mostrava chocado com a semelhança que o estudo dos "modos de pensar e sentir" do século XVI evocava da análise da "mentalidade primitiva" que Lévy-Bruhl "curiosamente recuperou para nós" (FEBVRE 1970, p. 483). 
Em 1934, Koyré publicou uma introdução a uma tradução do "Primeiro Livro" do De Revolutionibus Orbium Coelestium, de Nicolau Copérnico, no qual esboçava uma história do seu pensamento e expunha sua física. Em 1939, ele publicou seus Estudos Galilaicos, um livro constituído de três estudos sobre a história do pensamento galileano que já haviam sido publicados parcial ou inteiramente ao longo da segunda metade dos anos 30 e cujo objetivo era tratar do problema do nascimento da ciência moderna (sublinhe-se "do problema do nascimento"). A ciência moderna não decorreu de um desenvolvimento espontâneo da ciência ou da técnica medieval, de um acúmulo de experiência, de uma marcha progressiva, do aperfeiçoamento contínuo do espírito humano ou de uma evolução da lógica. Quando Koyré comentar, no final dos anos 40, as teses de Febvre sobre os limites e entraves à formação da ciência moderna no século XVI, seu combate contra o positivismo já havia sido lançado e uma concepção de história das ciências já havia sido avançada.

\section{Nascimento da ciência experimental}

Em 1948, Koyré publica dois artigos sobre o problema do nascimento da tecnologia: "Os filósofos e a máquina" (1991b) e "Do mundo do mais-ou-menos ao Universo da precisão" (1991a). No primeiro deles, trata-se de uma análise da tese psicosociológica sobre o maquinismo desenvolvida no livro de Pierre-Maxime Schul, Machinisme et philosophie, cuja segunda edição foi publicada em 1947. No segundo deles, que é um desdobramento do primeiro, é retomada a análise da questão sobre a não constituição da tecnologia na Grécia Antiga e busca-se oferecer um esboço das razões que explicam seu nascimento no século XVII. Nesse segundo artigo, Koyré analisa quatro obras editadas ou reeditadas entre 1945 e 1947: as de L. Munford, Willis L. Milham, L. Défossez e L. Febvre. O que está em jogo nesses artigos é pensar por que o surpreendente desenvolvimento teórico da ciência grega não conduziu à constituição da tecnologia no mundo antigo. Esse problema coloca imediatamente outro, aquele das relações entre ciência e técnica.

Em seus Estudos galilaicos (1992), Koyré não deu maior atenção ao problema da construção de instrumentos de precisão. Seu objetivo ali era analisar o nascimento da física matemática no início do século XVII. Era possível definir esse nascimento como uma revolução teórica, porque Galileu não acabou por destruir a física qualitativa antiga e medieval apresentando contra ela fatos da experiência ou evidências empíricas que a refutassem, mas opondo a ela outro sistema teórico. A revolução científica do século XVII não poderia assim ser caracterizada como uma revolução empírica, fundada na experiência e na correta observação dos fenômenos naturais, justamente porque ela buscou explicar o real a partir do ideal, substituir, na estrutura das ciências do real e na estrutura da natureza a que se dedicam essas ciências, a realidade empírica pelo mundo matemático e compreender o que "é" pelo que "não pode ser". "Explicação do real a partir do impossível"(KOYRÉ 1992, p. 257). Daí que, para caracterizar como experimental a ciência moderna, era preciso distinguir os conceitos de experiência e experimentação, pois a física matemática não 
poderia decorrer da experiência que ela iria condicionar. Por isso, a experiência, no sentido qualitativo, de experiência bruta, sensorial ou de observação do senso comum, apenas pôde desempenhar um papel de obstáculo ao nascimento da ciência moderna. A experimentação, "interrogação metódica da natureza", ao contrário, pressupunha uma linguagem e uma gramática que permitissem compreender as respostas produzidas por essa interrogação. A experimentação dependeu da resolução de um problema que é fundamentalmente filosófico e não empírico: a transformação das matemáticas na linguagem da natureza. Daí a importância filosófica - e não empírica - de Galileu no seu nascimento.

É justamente por isso que Koyré não dá maior atenção à construção de instrumentos em sua análise, na medida em que eles não desempenharam um papel primordial na transformação da estrutura conceitual e teórica da física; ao contrário, sua construção se tornou possível em função dessa transformação. Vemos que sua hipótese, segundo a qual a constituição da tecnologia tem como condição de possibilidade a elaboração de uma física matemática, já se encontra virtualmente aqui. Provavelmente o novo interesse intelectual pelo estatuto da tecnologia, traduzido pelas publicações dedicadas ao tema, tenha feito Koyré retomar e desenvolver essa hipótese alguns anos mais tarde. É aqui que se pode situar seu interesse pelo livro de Febvre.

\section{Epistemologia e ontologia}

Ao término da II Guerra Mundial, o primeiro curso ministrado por Koyré, já de volta a Paris, intitulava-se "As origens da tecnologia". No Anuário da EPHE, Koyré fixava a hipótese que resumia o seu curso em linha direta e complementar às análises desenvolvidas sobre a revolução científica do século XVII: "o nascimento da técnica científica oposta à técnica empírica do século XVI, assim como o nascimento do instrumento (instrumento de medida, instrumento ótico), encarnação da teoria no real que, somente ela, torna possível a constituição de um saber experimental e a redução do mundo ao numerus, pondus, mensura" (KOYRÉ 1986, p. 140). ${ }^{3}$ Vemos aqui já adiantada uma distinção entre dois tipos de técnica e a explicitação dos elementos de uma teoria do instrumento que se encontram no cerne da crítica feita por Koyré a Febvre em 1948.

Koyré concorda com o fato apontado por Febvre: até o século XVII, não havia instrumentos científicos ou de precisão, nem tampouco linguagem que pudesse traduzir ou expressar as mensurações, caso fosse possível realizá-las. No entanto, para Koyré, não são as mesmas razões que explicam esse estado. ${ }^{4}$ As condições de sua constituição são condições de pensamento, quer dizer, é a própria estrutura conceitual da ciência que permite compreendê-lo.

Se o nascimento da tecnologia dependeu da elaboração de uma física matemática, é preciso explicar por que os gregos não a elaboraram. Isso não

\footnotetext{
${ }^{3}$ Em 1946, ele ministrou em Nova York, na New School for Social Research, um curso com o título de "Ciência e técnica no mundo moderno" (KOYRÉ 1998). O texto desse curso foi publicado por Paola Zambelli, que redigiu uma interessante introdução à sua publicação.

4 "Por isso, mesmo estando mais do que de acordo com L. Febvre sobre a importância de sua ausência, não estou inteiramente satisfeito com a explicação que ele lhe dá" (KOYRÉ 1991a, p. 278).
} 
decorreu de nenhum tipo de carência ou insuficiência, mas de uma questão de pensamento ou pela "estrutura geral do 'mundo do mais-ou-menos'" (KOYRÉ 1991a, p. 277). Uma noção de realidade física: a realidade que nos cerca é movediça, imprecisa, incerta. Ela não é matemática, precisa e exata. É um contrassenso, portanto, querer aplicar a ela os conceitos matemáticos. Há um abismo entre eles e a realidade física. Na natureza, "há sempre uma margem de imprecisão" (1991a, p. 272) e nela não existem figuras geométricas. Não há, desse modo, nada de estranho nesta atitude.

Para Koyré, o pensamento grego permaneceu fiel a essa atitude: exceto pela arte, "a matéria desse mundo não poderia encarnar seres matemáticos" (KOYRÉ $1991 a$, p. 272). No entanto, os gregos admitiram que os céus e o movimento dos corpos celestes se prestavam às leis da geometria. Elaboraram, assim, uma astronomia matemática, uma cinemática celeste, realizaram cálculos, mediram e observaram os céus. E não porque os céus se prestassem "naturalmente" a essas leis: essa elaboração se assenta ou pressupõe esse estatuto ontológico que se atribui à realidade celeste, quer dizer, isso só foi possível porque consideraram que a essência dos céus era diferente daquela da Terra. Daí uma cosmologia: um cosmos dividido em duas realidades ontologicamente distintas, os mundos supra e sublunar; daí, uma epistemologia: uma física qualitativa, dedicada ao mundo do mais-ou-menos, oposta a uma astronomia matemática, dedicada ao mundo da precisão. Koyré retoma e desenvolve, portanto, um argumento que, de um modo distinto, já havia desenvolvido nos Estudos Galilaicos.

134 Desse modo, Koyré conclui que sem a transformação dessa concepção ontológica era impossível elaborar-se uma tecnologia. "A ciência grega não constituiu uma tecnologia verdadeira porque não elaborou uma física". E não o fez "porque aparentemente não procurou fazê-lo. E, sem dúvida, porque acreditou que isso não era factível" (KOYRÉ 1991a, p. 272). Foi essa concepção a que constituiu os limites ou formou um obstáculo para sua elaboração. Daí a importância das revoluções na história do pensamento, quer dizer, da destruição dessas concepções e da transformação de seus marcos. Daí também a importância que Koyré atribui, já em 1933, ao De Revolutionibus. Copérnico transformou a Terra em um astro como outro qualquer. Assim, ele não apenas a arrancava do centro do cosmos e a lançava nos céus, mas destruía a oposição entre mundo sub e supralunar, a oposição entre duas realidades ontologicamente distintas e que constituía o cosmos antigo e medieval. Foi essa destruição que levava a Terra aos céus ou ao mundo da precisão a que constituiu a condição que tornou possível a geometrização da natureza ou a constituição de uma nova atitude perante o mundo do mais-ou-menos no século XVII. Embora não dispusesse de instrumentos e meios de verificação de suas hipóteses, é o pensamento de Copérnico que tornou possível uma física matemática e, portanto, a tecnologia.

Assim, há uma inversão do argumento de Febvre. Não se pode dizer que a alquimia não se transformou em química no século XVI porque havia carência de instrumentos e de linguagem simbólica e porque o conhecimento teórico e o saber prático caminhavam separados nesse momento. Ela possuía um vocabulário próprio, formas de notação. Possuía certos utensílios. Acumulou 
observações e realizou experiências. Se quisesse, poderia ter utilizado a balança do ourives ou a do joalheiro, relativamente precisa, que já existia no século XVI.

Nunca realizou uma experiência exata, e isso porque nunca tentou fazê-lo. As descrições das operações alquímicas nada têm em comum com as fórmulas de nossos laboratórios: são receitas de cozinha, tão imprecisas, tão aproximativas, tão qualitativas quanto essas. E não foi a impossibilidade material para executar as medidas o que deteve o alquimista; ele não se serve delas mesmo quando estão ao seu alcance (KOYRÉ 1991a, p. 278).

Por isso, "não é o termômetro que Ihe falta, é a ideia de que o calor seja suscetível de uma medida exata" (KOYRÉ 1991a, p. 278). É exatamente esse o motivo pelo qual não se serve da balança. ${ }^{5}$

\section{O impensável e o nascimento dos instrumentos científicos}

Já em 1935, Koyré distinguia os conceitos de experiência e experimentação. No resumo do seu curso de 1945-1946, ele opunha técnica empírica e técnica científica. No segundo texto de 1948, ele distingue os conceitos de ferramenta (outil) e instrumento (instrument). Essa distinção permanecerá doravante em suas análises, certamente substituindo e precisando aquela oposição de 19451946 e inscrevendo-a naquela de 1935. O telescópio de Galileu é um instrumento científico em um sentido preciso; é um objeto construído a partir de uma teoria, a ótica, com uma finalidade teórica: "revelar aos nossos olhos coisas que são invisíveis a olho nu". É um "instrumento ótico", a encarnação da teoria, o devir-matéria da teoria e o devir-pensamento da matéria. "Permite ultrapassar os limites do observável, no sentido do que é dado à percepção sensível". Por isso, é preciso distingui-lo do conceito de ferramenta, que é

alguma coisa que, assim como já o havia percebido o pensamento antigo, prolonga e reforça a ação dos nossos membros, de nossos órgãos do sentido; alguma coisa que pertence ao senso comum. E que jamais pode nos fazer ultrapassá-lo. Isso que é, no entanto, a função própria do instrumento, que não é um prolongamento do sentido, mas, na mais forte e na mais literal acepção do termo, encarnação do espírito, materialização do pensamento (KOYRÉ 1991a, p. 279).

Daí uma segunda inversão importante da ideia de ciência experimental: a construção de instrumentos não é feita com o objetivo de verificação dos fatos ou de comprovação da teoria; o objetivo da experimentação é "descobrir de que maneira essa queda se realiza" não no espaço puro da física, "mas in rerum natura" (KOYRÉ 1991a, p. 286) ou, como escreve Jorland (1981, p. 53), o "de indicar as vias pelas quais as matemáticas se encarnam efetivamente na natureza". A verdade, portanto, não é uma simples consequência da verificação, pois a própria verificação pertence ao dispositivo experimental de produção da

\footnotetext{
${ }^{5}$ Koyré desenvolve o mesmo argumento em relação ao cronômetro, mostrando como sua construção no século XVII esteve ligada à resolução de problemas teóricos. Vê-se a diferença em relação a Febvre, para quem a ciência nasceria naquele século ligada à resolução de problemas práticos.
} 
verdade e que apenas se torna possível nos limites de uma nova configuração das relações entre o verdadeiro e o falso.

É assim que os instrumentos científicos não podem ser considerados como um resultado do aperfeiçoamento das ferramentas medievais e renascentistas. A técnica moderna é uma técnica de precisão. A revolução científica no século XVII e a construção de instrumentos implicam uma revolução técnica, pois as regras do ofício se transformam nas regras da precisão. Os objetivos teóricos da construção de instrumentos exigem profundas transformações na técnica. No caso da vidraçaria, por exemplo, é preciso construir lentes geométricas, dar a elas uma forma "exata e definida" (KOYRÉ 1991a, p. 280). É preciso construir "máquinas matemáticas" para talhá-las e produzi-las. Há uma transformação do pensamento técnico que marca o nascimento do pensamento tecnológico: "é na construção de instrumentos que se afirma o pensamento tecnológico". Para Koyré, não é uma carência nas condições industriais o que explica o estado da construção de lentes no Renascimento, pois as próprias condições industriais se transformam a partir das exigências teóricas.

Não há, assim, surpresa na constatação de que a construção de máquinas medievais e renascentistas era totalmente alheia aos cálculos. Elas eram concebidas e executadas segundo as regras do ofício, "a olho". Os livros que tratam delas fornecem sempre uma descrição aproximada de sua estrutura e funcionamento. Isso não quer dizer, para Koyré, que elas eram inferiores às 136 máquinas modernas ou que esse pensamento técnico carecia de ferramentas. Elas pertenciam ao mundo do mais-ou-menos. O mesmo pode-se dizer de sua afirmação de que a esses homens faltou a ideia de que a temperatura ou o tempo fossem passíveis de uma medida exata. Ele não está apontando aí uma inferioridade, um atraso ou uma insuficiência. Ele não está apontando aí uma falta ou analisando se seria ou não possível a possibilidade da ciência. Ele está apontando um impensável. A precisão e a exatidão na realidade terrestre e, portanto, a tecnologia e o maquinismo são impensáveis nessa época. O instrumento de precisão é impensável no mundo da imprecisão. ${ }^{6}$ Daí a importância da análise do nascimento dos instrumentos científicos.

Por isso, para Koyré, aquilo que para Febvre aparece como carência material e linguageira traduz a própria forma do pensar científico antigo e medieval. É isso que permite explicar, igualmente, o desenvolvimento das matemáticas a partir do século XVII. E aqui se definem claramente duas maneiras distintas de relacionar a história intelectual ou do pensamento com a história dos objetos técnicos ou com a história da construção de instrumentos científicos. Para Koyré, e ao contrário de toda uma tradição historiográfica e filosófica, não é a invenção de um instrumento que explica a transformação de uma concepção de natureza ou de mundo, mas é uma nova concepção de natureza ou de mundo que torna possível e explica a produção de instrumentos. Da mesma maneira, formula-se uma exigência teórica em relação ao tratamento das formas do pensamento

${ }^{6}$ Sobre a noção de impensável em Koyré, vide Jorland (1981, p. 69-70). 
outro: não se deve buscar explicá-las a partir de uma carência em relação ao nosso pensamento. A diferença não traduz uma falta.

\section{Idealismo}

Na verdade, não se pode dizer que Koyré criticasse o "inventário das possibilidades do espírito científico no século XVI" de Febvre. Koyré retomou-o em sua análise do nascimento da tecnologia, redefiniu os argumentos sobre suas condições e o desenvolveu no quadro de sua própria interpretação. Foi assim que Febvre considerou, em 1950, essa análise em um ensaio publicado nos Annales dedicado a comentar esse texto de 1948. Imediatamente, Febvre rechaçava as conclusões de Koyré, afirmando que ele prolongava suas "constatações no sentido de um idealismo total" (FEBVRE 1950, p. 26). Para Febvre, a afirmação de que não fora o termômetro que faltou aos alquimistas do século XVI, mas o pensamento ou a ideia de que o calor fosse suscetível de uma medida exata, soava demasiadamente idealista. Mas o interessante era que Febvre não questionava sua análise sobre o nascimento da tecnologia, mas a dos efeitos desse acontecimento sobre a mentalidade da época. A resposta de Febvre e seus desdobramentos são interessantes porque evidenciam não simplesmente um desencontro ou uma irreconciliável divergência de interpretações, mas a constituição de dois modos de abordagem do passado das ciências e das formas de saber inatuais. Se Febvre e Koyré se encontravam, nos anos 30, de certa forma, teoricamente próximos em virtude do combate à dominante interpretação positivista - e mesmo às teses deterministas do materialismo histórico - e em um esforço de fundar novas abordagens da história das ciências, aqui se abria um forte ponto de desencontro - embora não possamos nos esquecer de que Koyré, em sua recensão, colocou-se mais próximo de Febvre do que de outras interpretações na medida em que se somou ao seu esforço de pensar a ciência e a tecnologia de uma perspectiva crítica aos determinismos econômicos e sociológicos. No núcleo desse desencontro, podemos identificar ao menos três problemas: a relação entre ciência e realidade; a compreensão do que constitui o tempo de que trata a história; e a diferença entre os conceitos de mentalidade e pensamento.

Febvre rechaça o argumento do autor dos Estudos Galilaicos propondo uma leitura do Diário de Viagem de Monconys, conselheiro do Rei, publicado em 1665. Monconys é curioso e interessado por invenções. Interessa-se por máquinas, pela observação de experiências. Visita cientistas em seus laboratórios. Em Florença, visita Torricelli. Não apenas adquire instrumentos de observação, mas conhece sua teoria. Não é um tolo. É um sábio que conhece os "últimos progressos da técnica científica" (FEBVRE 1950, p. 28). Monconys "se move em um universo povoado de lunetas, de telescópios, também de microscópios, e já de barômetros". É "o contrário de um tolo, de um ignorante, de um crédulo. Mas..." (FEBVRE 1950, p. 28-29) ele vive ainda no mundo do mais-ou-menos, sobretudo no mundo em que reina soberano o "ouvir dizer", em que não há crítica do fato. Monconys visita Loudun para observar as marcas que o demônio deixou sobre as possuídas. Anota e aconselha receitas de simpatias para curar 
reumatismos, febres e feridas de cachorros picados por cobras. Simplesmente, acredita nelas. Já longe do século XVI, um homem cultivado, cercado por instrumentos. Monconys, um crédulo ${ }^{7}$

Duas questões podem ser destacadas a partir daí. Para confirmar a credulidade, Febvre desloca os seus contra-argumentos para o que em geral chamaríamos de história da medicina (as receitas em que acredita Monconys são ligadas às práticas de cura). Assim, circunscreve a "ciência experimental" à fisiologia do século XIX. Ora, isso quer dizer que, mesmo no século XVII, depois de Galileu e Descartes, os homens ainda não dispunham de critérios seguros para discriminar o possível e o impossível. Qual critério permitiria rechaçar a ação do demônio? Ou a ideia de que o emprego de pedras retiradas do corpo de serpentes e aplicadas sobre a ferida de um cachorro picado por uma cobra extrairia todo o veneno do animal? Febvre retoma o argumento desenvolvido em Rabelais: "não há como se assenhorear do real" (FEBVRE 1970, p. 30) e, portanto, estabelecer que certos fatos ou fenômenos são impossíveis. A soberania do "ouvir dizer" perdurará

até o dia em que, tendo os primeiros fisiologistas começado a construir, de Lavoisier a Claude Bernard, o edifício de uma ciência fundada na observação e experimentação, tornar-se-á possível reconstituir, partindo das primeiras aquisições, esta ciência que recua a cada dia as fronteiras da vida - e por meio de uma marcha prudente do conhecido em direção ao desconhecido, não digo, certamente, assenhorear-se do universo físico, mas lançar sobre ele redes sucessivas de pontos de apoio (FEBVRE 1950, p. 30).

Eis a noção de epistemologia em Febvre, na qual o instrumento tem primazia sobre a concepção de ciência e sobre a concepção de natureza; noção essa que destitui da análise epistemológica o problema metafísico e ontológico ou que, no limite, relega-o à condenação idealista. Febvre mantém a oposição tradicional, no exame histórico do passado, entre fenômenos de mentalidade e fatos de civilização material, quer dizer, entre história das ideias e história econômica, social ou material. Em seu esforço de pensar o modo como uma concepção de ciência se articula com uma concepção de mundo, é a destruição dessa clivagem o que está em jogo em Koyré.

\section{História da ciência e história das ciências}

De nossa parte, não acreditamos que essa discussão tenha se encerrado aí, pois Koyré, em ao menos duas ocasiões, buscou, se não se defender, ao menos se explicar em relação à imputação de idealismo. Suas colocações nos ajudam a compreender com clareza o que estava em jogo nessas diferentes maneiras de conceber a história. Em um texto de 1953 em que retoma o problema da

\footnotetext{
7 Dito de outro modo, credulidade e ciência moderna convivem tranquilamente em pleno século XVII. Febvre rechaça, por outras vias, o argumento positivista segundo o qual a ciência moderna teria substituído as concepções teológicas e metafísicas de natureza (Cf. REDONDI 1983, p. 319-320). Mas, em função do conceito de mentalidade, ele jamais poderia admitir nessa convivência a coexistência de temporalidades distintas em uma mesma época.
} 
dificuldade material da experimentação nos primórdios da ciência moderna, Koyré faz, certamente, uma precisão em relação a esse argumento de Febvre embora não haja qualquer referência a ele. Após reafirmar que a ciência moderna se constituiu substituindo o mundo do mais-ou-menos "por um Universo de medida e precisão", ele esclarece que essa substituição implicou a exclusão desse Universo daquilo que não poderia "ser submetido à medida exata". O argumento de Koyré só se aplica às ciências exatas - e, de fato, ele havia analisado os exemplos do termômetro, do cronômetro e do telescópio. Isso não significa uma impossibilidade de epistemologização das qualidades. As ciências ditas naturais não as rejeitam, mas seus conceitos não são matemáticos. É, portanto, em uma base conceitual diferente que elas podem ser interrogadas: "nem na botânica, nem na zoologia, nem mesmo na fisiologia e na biologia as medidas exatas tiveram um papel a desempenhar" (KOYRÉ 1982c, p. 294). Disso não se deve concluir que a qualidade ou o mundo natural de nossa percepção não possam se tornar objeto da ciência: "a qualidade pode ser ordenada, mas não medida" (KOYRÉ 1982c, p. 294). Isso explica por que não há história natural no século XVII, mas, ao mesmo tempo, o que a torna possível no século XVIII. Era preciso que se abandonasse a excessiva geometrização cartesiana da matéria para poder pensá-la de outro modo. E isso não acontecerá antes de Newton. Monconys pode ser um crédulo em meados do século XVII, mas a estrutura conceitual das ciências exatas (da física) e do Universo a que elas se dedicam exclui a priori todo e qualquer conceito qualitativo. Os conceitos não matemáticos podem se constituir no quadro de outras ciências.

Há, assim, uma heterogênese das ciências. Mas aí já não estaríamos falando de ciências no plural? E já não estaríamos distinguindo fatos e conceitos em séries históricas diferentes que implicariam temporalidades distintas ou heterocronias em uma mesma época? O argumento programático de uma história das ciências e das técnicas de Febvre, sobre o qual falamos no início deste artigo, inscreve-se no quadro de uma história totalizante e pressupõe, portanto, um tempo histórico idêntico a si mesmo. Em função do conceito de mentalidade, esse princípio unificador das ideias de uma época, Febvre jamais poderia admitir nessa convivência a coexistência de temporalidades distintas em um mesmo período. Daí que, para ele, embora fosse preciso reconhecer na física matemática a gênese dos instrumentos de medida, era preciso ao mesmo tempo reconhecer que o seu aparecimento não alterava em nada a psicologia coletiva da época. Sob a distinção-indistinção entre uma história das ciências exatas e naturais talvez haja um desacordo sobre o próprio tempo da história da ciência ou das ciências. Desse modo, uma primeira conclusão à qual a análise desse debate nos permite chegar é a de que um dos elementos centrais em que se assenta o desacordo de fundo entre Koyré e Febvre diz respeito à concepção de tempo histórico com a qual lidam uma história das mentalidades e uma história do pensamento. É isso que explica em parte a diferença brutal entre duas interpretações contemporâneas de Copérnico. ${ }^{8}$

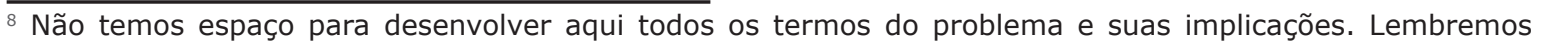


Esse argumento nos conduz diretamente ao problema da heterogênese do tempo. Para Febvre, não é possível situar a gênese do mundo moderno no século XVI. Uma afirmação de Koyré em "A contribuição científica da Renascença" não deixa de ser interessante nesse sentido: a evolução científica "se processa à margem do espírito renascente e à margem da Renascença propriamente dita ou do 'tudo é possível' que caracteriza a mentalidade da Renascença" (KOYRÉ 1982a, p. 49, grifos meus). Copérnico não está, certamente, à frente de seu tempo. É um humanista. Na época de estudante, ele se deixou "penetrar pela mentalidade 'renascente' e sofreu fortemente a inspiração neoplatônica e pitagórica que dominava a Itália" (KOYRÉ 1961, p. 22). Vemos como a mentalidade não é um princípio de unificação das ideias de uma época, como Koyré não aceita traduzir uma mentalidade por uma psicologia coletiva. A mentalidade renascente inspira Copérnico, mas, simultaneamente, o movimento de pensamento, no interior do qual é preciso situar (de Cusa a Kepler e a Galileu) a filiação das ideias que conduziram à destruição do cosmos fechado e à elaboração de uma nova ontologia, encontra-se à sua margem. Isso implica pensar que, em um mesmo tempo, há tempos à margem, linhas de evolução paralelas cujas espessuras singulares são postas em relevo pela serialização dos fatos e fenômenos - é precisamente a série astronomia que está aqui à borda. Por isso, a mentalidade não corresponde à forma do próprio tempo ao qual pertencem os homens de uma época. O tempo de uma natureza mágica não é o mesmo tempo da realidade da astronomia matemática. Mas é nesse tempo que é preciso situar a

140 constituição da teoria heliocêntrica. Nesse tempo paralelo, à margem das ideias renascentes. E, como aponta Koyré, "não é menos verdadeiro o fato de que a destruição da síntese aristotélica constitui a base preliminar e necessária dessa evolução" (KOYRÉ 1982a, p. 49). A destruição da síntese aristotélica conduz a uma bifurcação ou a uma multifurcação no próprio tempo, à constituição de linhas paralelas de evolução. Daí que a monogênese do tempo conduza a análise de Febvre à impossibilidade de situar no século XVI o nascimento do mundo moderno. Como ele insiste ao longo de Rabelais, será preciso ultrapassar esse tempo ou aguardar por outro tempo. Daí que a heterogênese do tempo conduza a análise de Koyré a situar em Copérnico e no século XVI a própria condição que torna possível não apenas o mundo, mas a própria ciência moderna - mesmo que Copérnico não seja ainda copernicano.

\section{O pensamento como diferença}

Certamente, para Febvre, essa história do pensamento só poderia ser caracterizada como idealista e Monconys permanecia irremediavelmente um crédulo. A revolução descrita por Koyré, para Febvre, não afetava em nada a crença ou mentalidade dos homens em pleno século XVII. Sua psicologia

apenas que a objeção principal de Febvre girava em torno da discriminação do possível e do impossível. No Rabelais, ele havia insistido nessa questão: faltou aos homens do século XVI o sentido do impossível. Por isso, tudo era demonstrável, tudo era possível. Esse argumento implicava, para Koyré, um problema ontológico e não se explicava pelos traços de uma mentalidade prélógica. Após destruir a síntese aristotélica, a Renascença foi conduzida a uma ontologia mágica. Pretendemos desenvolver a análise desse problema em outro artigo. 
permanecia, então, a mesma. Querer se dedicar, portanto, aos seus textos e pensamento, seria se prolongar no idealismo, o que Febvre reprovava nos filósofos desde os anos 1930. Koyré, todavia, não falava de uma revolução que afetava a psicologia coletiva, mas a estrutura ou a forma do pensamento científico. O que está, portanto, em jogo nessas diferentes compreensões de Febvre e Koyré é uma questão de fundo: a divergência sobre os pressupostos de uma história das mentalidades e uma história do pensamento. Segundo Pietro Redondi,

\begin{abstract}
desde 1926, em uma resenha de um livro de Louis Rougier, Koyré tomava distância de uma noção de 'mentalidade' em nome da 'identidade formal do pensamento'. Utensilagem mental, psiquismos e mentalidades eram categorias relevando de um relativismo histórico no qual Koyré não podia dissolver a permanência do pensamento em seus domínios intelectuais diferentes (REDONDI 1983, p. 327).
\end{abstract}

Na resenha à que se refere Redondi, Koyré opõe à noção de mentalidade a noção meyersoniana de pensamento. Isso não quer dizer que ele descarte totalmente aquela noção. Sem dúvida, há "atitudes mentais" variáveis: individuais, profissionais e sociais. Há uma atitude mental religiosa e irreligiosa, calculista ou imprecisa. Mas Rougier (1925) dissolvia a noção de pensamento na de mentalidade e o definia como "conjunto de crenças e de superstições em curso em uma época" (KOYRÉ 1926, p. 466). Assim, a mentalidade escolástica não seria nada além de um "paralogismo".

Uma nota de seu artigo sobre Paracelso, aparentemente deslocada e que poderia surpreender um leitor desavisado, permite-nos pensar o problema. Ela é particularmente interessante porque ressoa o debate sobre o prélogismo. Ei-la: "Para evitar todo mal-entendido, não admitimos absolutamente a variabilidade das formas de pensamento, nem a evolução da lógica" (KOYRÉ 1971, p. 78). Não se pode querer ver aqui qualquer manifesto em favor da fixidade da razão. Vimos mais acima como Koyré rechaça a compreensão de uma evolução da lógica, de uma história do pensamento como evolução da razão de suas formas primitivas a sua forma atual, de inspiração positivista. Se não se pode falar em evolução da lógica, não se pode tampouco evocar, para explicar a diferença das formas ou estruturas de pensamento, um critério antievolucionista, o da variabilidade das formas. Quer dizer, a diferença das formas de pensamento não se explicaria por uma filiação evolutiva, mas por uma variabilidade sem filiação. Esse é justamente o caminho a que conduzia o conceito de mentalidade: poderia se opor uma mentalidade lógica a uma mentalidade prélógica; um antievolucionismo seria substituído por um variacionismo.

É justamente nesse cruzamento que se encontravam Febvre e Koyré por volta de 1930 - e foi nele que as histórias do pensamento e das mentalidades se constituíram -: as formas (para nós) confusas do pensamento e as concepções mágicas do Renascimento não podiam mais ser interpretadas sob a grade evolucionista ou comtiana. Mas não apenas Febvre e Koyré. A geração do entreguerras se viu diante de novas concepções que colocavam em xeque noções importantes oriundas do século XIX. Não devemos esquecer que o final 
do século XIX e o início do século XX foi a época que assistiu à emergência da psicanálise, da linguística e, de maneira geral, das ciências humanas. Essas "contraciências", como as definiu um arqueólogo desse movediço terreno intelectual, descentravam o sujeito em relação à sua consciência e vontade. Uma zona obscura e até então desconhecida do sujeito - cujas potencialidades o surrealismo procuraria explorar desde o início dos anos 20 - era posta em relevo. Sob sua forma trágica, não esqueçamos, a loucura voltava a assombrar a razão nessa época.

O primitivo de Lévy-Bruhl (com sua concepção mágica ou mística do mundo) era uma figura importante dessa cena intelectual. Ele era absolutamente distinto daquele das teorias evolucionistas ou daquele concebido pelos antropólogos britânicos. Ao evidenciar uma forma de pensamento outra, absolutamente distinta daquela que até então se considerava sua forma exclusiva, seu advento punha em xeque os fundamentos da razão categórica. O conhecimento seguro do mundo não podia mais se assentar nas simples evidências da realidade concreta a partir do princípio de identidade e não contradição. Um conhecimento homogêneo e global de uma realidade unitária era posto em questão. Com essa "descoberta" do pensamento outro, uma concepção essencialista e evolutiva da razão, bem como os princípios filosóficos e antropológicos em que se assentava sua interpretação se transformam em problema. O pressuposto teórico do qual partia o trabalho de Louis Rougier assentava-se na interpretação de Lévy-Bruhl e supunha uma refutação da "crença na identidade de um espírito humano 142 perfeitamente semelhante a si mesmo, do ponto de vista da lógica, em todos os tempos e em todos os países" (ROUGIER 1924, p. 208)..$^{9}$

É essa forma de variabilidade que Koyré não pode admitir no conceito de mentalidade. E isso por, ao menos, dois motivos. Primeiramente, porque, no intuito de considerar a diferença das formas de pensamento por meio da ideia de uma variabilidade sem filiação, forjava-se uma explicação totalmente desistoricizada. Não é, portanto, apenas a dissolução da permanência no relativismo o que Koyré não pode admitir no conceito de mentalidade, mas o rechaço da historicidade do pensamento. Mentalidade é um conceito desprovido de historicidade. Sua aplicação na história estabelece uma identificação no tempo (mentalidade escolástica, mentalidade do século XVI), uma variação. Mas não há historicidade nessa variação. Que é apenas uma variação de nosso pensamento. É preciso identificar uma forma de pensamento outra não como uma variação, mas como uma diferença, em sua própria historicidade. A credulidade sem limites e o "tudo é possível" que caracterizam a Renascença não se devem ao caráter primitivo e prélógico de sua mentalidade, mas à ontologia mágica que os torna possível. Por isso, Koyré se esforça em apontar a historicidade dessas noções: elas nascem nos escombros da síntese aristotélica e da ontologia medieval.

Em segundo lugar, se Koyré critica o emprego do conceito de mentalidade de Rougier, é porque ele rechaça a ideia de variabilidade. O pensamento outro deve ser tratado como uma diferença e não como uma variação. Ele distingue,

${ }_{9}^{9}$ Como se reconhece, essa é uma afirmação textualmente retirada do próprio Lévy-Bruhl (1928, p. 7). 
portanto, o conceito de mentalidade do conceito de pensamento. O século XVI não se caracteriza por uma forma prélógica de pensamento porque nessa época se acreditava na astrologia, na alquimia, na magia, nos gnomos e no lobisomem. Isso era, então, "razoável e racional" (KOYRÉ 1971, p. 79). Há, portanto, uma forma de raciocínio, embora ela seja absolutamente diferente da nossa. Essa é a dificuldade própria de uma história do pensamento.

O que há de mais difícil - e mais necessário - quando se estuda um pensamento que não é o nosso, é - como o mostrou admiravelmente um grande historiador - menos aprender o que não se sabe e o que sabia o pensador em questão, que esquecer o que nós sabemos ou acreditamos saber. Às vezes, acrescentemos, é necessário não apenas esquecer verdades que se tornaram partes integrantes do nosso pensamento, mas mesmo adotar certos modos, certas categorias de raciocínio ou ao menos certos princípios metafísicos que, para pessoas de uma época passada eram tão válidos e formavam bases tão seguras de raciocínio e de pesquisa quanto são para nós os princípios da física matemática. Seria preciso assim admitir o princípio de equivalência da parte com o todo, princípio cuja importância, para o pensamento primitivo, foi estabelecida por Lévy-Bruhl, e para o pensamento metafísico, por Hegel (KOYRÉ 1971, p. 77).

O fato de Koyré evocar, numa passagem programática e metodológica, o nome de Lévy-Bruhl não deve nos chocar. Na década de 1920, Koyré esteve bastante interessado em acompanhar a publicação e os debates sobre seu trabalho, certamente, na esteira de suas implicações para a teoria de Meyerson. Mas não apenas por isso, pois se tratou de um dos grandes acontecimentos filosóficos do entreguerras. Desde ao menos 1923, o prélogismo era objeto de profundas críticas e discussões. Em 1930, Koyré (1930) publicou uma resenha de L'âme primitive, na qual não apenas apresentava ao público de língua alemã suas teses fundamentais como respondia às objeções que a elas se dirigiam havia alguns anos. Essa passagem acima citada nos mostra que o autor de La mythologie primitive desempenhou um papel importante no trabalho do filósofo francês de origem russa em ao menos dois aspectos: o conjunto de noções primitivas estabelecidas por Lévy-Bruhl, quer dizer, de concepções místicas e mágicas indissociáveis de uma determinada compreensão da natureza, permitia-lhe pensar de uma nova maneira a filosofia de um Jacob Boehme, dos mestres do teósofo teutônico e do próprio Renascimento; sob a unidade puramente formal do pensamento humano, era possível reconhecer formas de pensamento diferentes daquelas às que estávamos habituados: entre a escolástica medieval e a filosofia matemática da natureza, eis aí a ontologia mágica renascentista. Não devemos, portanto, esquecer que essa citação acima é extraída de um texto sobre Paracelso, no qual seu autor procurava definir os limites de um modo de pensar que não era nem aristotélico e nem tampouco galileano. A noção de pensamento mágico, com a qual se poderiam definir os contornos precisos do pensamento renascentista, forjava-se por meio de sua leitura. Em segundo lugar, na medida em que o programa explicitado nessa citação traduzia uma exigência do pensamento de Lévy-Bruhl, aquela de não projetar as formas de nosso raciocínio ou de nossas crenças sobre aquelas que 
não são as nossas. Vemos que em Lévy-Bruhl se encontrava, no entreguerras, uma chave para se compreender pensamentos e crenças diferentes dos nossos e constatamos por que as histórias do pensamento e das mentalidades podiam aí se encontrar, mas, ao mesmo tempo, por que não podiam prolongar esse encontro: Koyré não podia concordar com a concepção de incomensurabilidade por meio da qual Lévy-Bruhl radicalmente opunha as mentalidades lógica e prélógica. ${ }^{10}$ Partindo dessa hipótese e aplicando-a à história da filosofia medieval, Rougier era levado a esvaziar de sentido a noção de pensamento. Anos mais tarde, quando Koyré comentaria o trabalho do autor do Rabelais, sua posição em relação a esse conceito já estava definida. ${ }^{11}$

Tratava-se, portanto, de distinguir mentalidade e pensamento e evitar a dissolução desse conceito naquela noção. Daí justamente sua crítica de 1926 à noção de mentalidade em nome da identidade formal do pensamento: o fato de os homens do passado terem pensado coisas tão estranhas e diferentemente de nós não significa dizer que eles não pensaram. A escolástica não é uma "aberração estranha da inteligência humana" (KOYRÉ 1926, p. 467). Há um pensamento escolástico: "um conjunto de esforços filosóficos, de pensamentos profundos, de análises sutis e precisas, de psicologia instruída, de metafísicas coerentes, tão dignas de estudo quanto as filosofias antigas" (KOYRÉ 1926, p. 467). Há, portanto, um pensamento, um esforço de intelecção, de explicação do real, de compreensão do mundo. E embora um escolástico e um homem moderno entendam de maneira profundamente diferente o que constitui a realidade, a verdade e o mundo, ambos se esforçam em compreendê-los. É o que torna efetivamente possível uma história do pensamento: reconstituir estruturas conceituais e formas de pensamento em sua própria singularidade e

\footnotetext{
10 Para Paola Zambelli (1995), a noção de mentalidade desempenhou um papel metodológico fundamental no trabalho de Koyré. Ela formaria, ao lado da descrição fenomenológica, a base da metodologia koyreana. Todavia, a importância de Lévy-Bruhl para o trabalho do autor dos Estudos Galilaicos não se restringiria a esse aspecto metodológico. Segundo a historiadora italiana, todo o devir intelectual de Koyré teria sido marcado, desde sua fixação em Paris, por volta de 1912-1913, pelas pesquisas sociológicas de Lévy-Bruhl, que teria influenciado inclusive a escolha do tema de sua tese nos anos 1920. Na esteira de Yehuda Elkana (1987), que o transformou em um sociólogo "do conhecimento da alta cultura", Zambelli esforça-se por inscrevê-lo na tradição da escola sociológica francesa e em seus estudos das representações coletivas. Para ela, isso evidencia-se no modo como ele estudou "os pressupostos metacientíficos expressos na linguagem científica". Logo no início de Fonctions méntales, conforme ela sublinha, o exemplo que Lévy-Bruhl dava de representações coletivas era exatamente a linguagem. A partir daí, ela procura estabelecer toda uma série de relações (mesmo pessoais) que demonstrariam o modo como o pensamento de Koyré foi "influenciado" por Lévy-Bruhl. Surpreendentemente, ela desconsidera a importância teórica e metodológica de Émile Meyerson no trabalho de Koyré. Foi, no entanto, nele que Koyré encontrou o interesse filosófico pelo estudo histórico de teorias nas quais não acreditamos mais. Ao mesmo tempo, ela desconsidera que nessa passagem Koyré cita um "grande historiador" - Paul Tannery, segundo Redondi (1986, p. XII e ss.) - de quem teria tomado o preceito de analisar o pensamento no passado a partir de suas próprias categorias. Isso mostra a complexidade da noção de "influência". Finalmente, seria preciso desenvolver o argumento segundo o qual o pensamento científico, para Koyré, é uma representação social. Esse argumento não conduziria à afirmação que de seria possível entender o pensamento de um Galileu por meio das representações sociais da Florença de seu tempo? Dito isso, não se trata de questionar a importância de Lévy-Bruhl no trabalho de Koyré - sobre a qual a historiadora italiana lançou luzes importantes, embora, a nosso ver, superestimando-a - nem tampouco de refutar a importância da constituição das ciências humanas e particularmente da sociologia no modo como a história (e não apenas a das ciências) seria escrita no entreguerras. Em um artigo anterior, Paola Zambelli (1987) havia insistido na existência de uma diferença metodológica entre o Koyré dos anos 50 e aquele dos seus anos de formação. Essa distinção e a própria ideia de um Koyré "late bloomer" desaparecem nesse artigo de 1995.

${ }_{11}$ Podemos acreditar que Lévy-Bruhl estivesse de acordo com essa crítica, pois ela foi publicada na Revue Philosophique, que ele então dirigia - e que publicou um grande número de recensões de Koyré no entreguerras. De qualquer forma, não devemos esquecer que apenas no final de sua vida ele renunciou à hipótese de uma distinção radical entre duas formas de mentalidade. A resenha de Koyré é importante, pois nela ele fazia o casamento entre esquemas explicativos bastante diferentes, o de Lévy-Bruhl e o de Meyerson.
} 
como diferença. Isso explica que a interpretação de Koyré das análises de Lévy-Bruhl seja bastante distinta daquela de Rougier. Um primitivo, tanto quanto um escolástico, pensa. Mas daí também o distanciamento de Koyré das pesquisas de psicologia coletiva.

Essas conclusões também nos permitem especular sobre se essa distinção entre mentalidade e pensamento não é o que torna possível à própria antropologia, na medida em que se afasta do prélogismo, pensar no pensamento selvagem, no pensamento em seu estado selvagem. Mas não apenas à antropologia, pois, nesta mesma época, alguns anos antes da publicação do livro de Claude Lévi-Strauss, na esteira da afirmação koyreana da existência e da necessária distinção que caracteriza a singularidade do "pensamento técnico e do pensamento científico", era preciso, reivindicava Pierre Francastel (1956, p. 108) para as artes, "acrescer aquela que conduz ao reconhecimento de um pensamento plástico". O problema, então, que caberia desenvolver em outra pesquisa seria o de analisar se esse esforço koyreano de compreender o pensamento outro em sua diferença e singularidade não constitui a condição de possibilidade de todas as pesquisas que, na França, a partir do final dos anos 50 e início dos anos 60, buscaram reconhecer na ciência, na arte, na literatura, no cinema, etc., atividades criadoras e produtoras de pensamento. Não é, portanto, a simples permanência do pensamento que é preciso destacar, mas a multiplicação do "pensa-se", mas sempre de modos diferentes que é preciso reconhecer.

\section{Referências bibliográficas}

COMTE, Augusto. Curso de Filosofia Positiva. Traduzido por José Arthur Giannotti. São Paulo: Abril Culturas, 1983 [1830-1842].

DUHEM, Pierre. Sauver les apparences: sur la notion de Théorie physique. Paris: Vrin, 2003 [1908].

ELKANA, Yehuda. Alexandre Koyré: between the history of ideas and sociology of disembodied knowledge. Special Issue: Science: The Renaissance of a History. Proceedings of the International Conference Alexandre Koyré. History and Technology, v. 4, n. 1-4, p. 115-148, 1987.

FEBVRE, Lucien. De l'à peu près à la précision en passant pour l'ouï-dire. Annales ESC, v. 5, n. 1, p. 25-31, 1950.

. O problema da descrença no século XVI: a religião de Rabelais. Traduzido por Rui Nunes. Lisboa: Início, 1970 [1942].

- Rapport de Lucien Febvre à l'Assemblée des Professeurs du Collège de France sur la création d'une chaire d'Histoire de la pensée scientifique. In: KOYRÉ, Alexandre. De la mystique à la science: cours, conférences et documents - 1922-1962. Editados por Pietro Redondi. Paris: EHESS, 1986.

. Réflexions sur I'histoire des techniques. Annales ESC, v. 7, n. 36, p. 531-535, 1935. 
Vivre I'histoire: propôs d'initiation. In:

Combats pour

I’histoire. Paris: Armand Colin, 1995.

FRANCASTEL, Pierre. Art et technique auX XIXe et XXe siècles. Paris: Gallimard, 1956.

GATTINARA, Enrico Castelli. Epistémologie, histoire et histoire des sciences dans les années 1930. Revue de Synthèse, n. 1, p. 9-36, 1998.

GOLDMANN, Marcio. Razão e diferença: afetividade, racionalidade e relativismo no pensamento de Lévy-Bruhl. Rio de Janeiro: EdUFRJ/Grypho, 1994.

JORLAND, G. La science dans la philosophie: les recherches épistémologiques d'Alexandre Koyré. Paris: Gallimard, 1981.

KOYRÉ, A contribuição científica da Renascença. In:

Estudos de história do pensamento científico. Traduzido por Márcio Ramalho. Rio de Janeiro, Forense; Brasília: EdUnB, 1982a.

- Introduction. In: COPERNIC, Nicolas. Des Révolutions des Orbes Célestes. Traduction, avec introduction et notes par A. Koyré. Paris: Félix Alcan, 1934.

. [Resenha de] Die Seele der Primitiven. Deutsche Literaturzeitung, v. 48 , n. 48 , p. 2294-3000, 1930.

. De la mystique à la science: cours, conférences et documents 1922-1962. Editados por Pietro Redondi. Paris: EHESS, 1986.

Do mundo do "mais-ou-menos" ao universo da precisão. In:

Estudos de História do Pensamento Filosófico. Rio de Janeiro: Forense, 1991a.

. Études d'histoire de la pensée philosophique. Paris: Gallimard, 1971.

. Estudos galilaicos. Traduzido por N. da Fonseca. Lisboa: Dom Quixote, 1992 [1939].

. Histoire de la philosophie. Revue philosophique de la France et de l'etranger, n. 51, p. 462-469, 1926.

. La Révolution Astronomique. Paris: Hermann, 1961.

. Leonardo Da Vinci 500 anos depois. In: . Estudos de história do pensamento científico. Rio de Janeiro, Forense; Brasília: EdUnB, 1982b.

- Os filósofos e a máquina. In: Estudos de história do pensamento filosófico. Traduzido por Maria de Lourdes Menezes. Rio de Janeiro: Forense, 1991b.

Paracelso. In: Mystiques, spirituels, alchimistes du XVIe siècle allemand. Paris: Gallimard, 1971.

Present trends of French philosophical thought. Journal of the History 
of Ideas, v. 59, n. 3, p. 521-548, 1998. (Editado e publicado por P. Zambelli).

. Uma experiência de medida. In: Estudos de história do pensamento científico. Rio de Janeiro, Forense; Brasília: EdUnB, 1982c. LÉVY-BRUHL, Lucien. Les fonctions mentales das les sociétés inférieures. 9a edição. Paris: Félix Alcan, 1928 [1910].

RANCIÈRE, Jacques. O conceito de anacronismo e a verdade do historiador. Traduzido por Mônica Costa Netto. In: SALOMON, Marlon (org.). História, verdade e tempo. Chapecó: Argos, 2011.

REDONDI, Pietro. Préface. In: KOYRÉ, Alexandre. De la mystique à la Science: cours, conférences et documents (1922-1962). Paris: EHESS, 1986.

. Science moderne et histoire des mentalités. La rencontre de Lucien Febvre, Robert Lenoble et Alexandre Koyré. Revue de Synthèse, n. 111-112, p. 309-332, 1983.

ROUGIER, Louis. La mentalité scolastique. Revue philosophique de la France et de l'etranger, n. 97, p. 208-232, 1924.

. La scolastique et le thomisme. Paris: Gauthier-Villars, 1925.

ZAMBELLI, Paola. Alexandre Koyré versus Lucien Lévy-Bruhl: from collective representations to paradigms of scientific thought. Science in Context, v. 8, n. 3, p. 531-555, 1995.

. Hermétisme, mystique, empirisme. Special Issue: Science: The Renaissance of a History. Proceedings of the International Conference Alexandre Koyré. History and Technology, v. 4, n. 1-4, p. 465-483, 1987. 